\title{
PERBAIKAN PROSES PEMBUATAN BAKPAO SEHAT DAN NIKMAT DI KELOMPOK PENGUSAHA BAKPAO TEGAL BESAR-JEMBER
}

\author{
Siti Djamila \#1, Titiek Budiati ${ }^{* 2}$, Iswahyono ${ }^{\# 3}$, Amal Bahariawan*4 \\ \#Jurusan Teknologi Pertanian, Politeknik Negeri Jember \\ Jalan Mastrip, Jember \\ 1umidjamila@yahoo.co.id; 3is tep@yahoo.co.id; 2titik.budiati@gmail.com \\ 4amalbahariawan68@gmail.com
}

\begin{abstract}
ABSTRAK
Selama ini pembuatan bakpao dilakukan dengan menggunakan peralatan yang sangat sederhana. Seperti untuk pembagian adonan menjadi bagian yang kecil - kecil dilakukan dengan menimbang satu persatu adonan, selain itu proses pengembangan adonan dilakukan dengan cara menutup adonan yang ada dalam loyang-loyang yang sudah disusun dengan menggunakan penutup plastik. Dengan pelaratan yang ada tersebut kualitas dan kuantitias produksi bakpao belum maksimal dan waktu yang diperlukan cukup lama 5-7 jam sekali proses produksi. Tujuan dari kegiatan pengabdian ini adalah untuk membantu kelompok pengusaha bakpao terutama dalam peralatan proses produksi bakpao sehingga kualitas dan kuantitas bakpao dihasilkan meningkat serta waktu proses lebih singkat. Target yang ingin dicapai adalah pembagian adonan dilakukan dengan alat pembagi adonan (divider) dan pengembangan adonan dilakukan dengan lemari pengembang (proofer). Metode yang digunakan adalah untuk pembagian adonan dilakukan dengan mesin pembagi adonan sistim multi blade dengan tenaga pemotong pneumatic, sedangkan untuk pengembang menggunakan lemari pengembang yang dilengkapi dengan suhu dan kelembaban udara dikontrol secara otomatis menggunakan termo kontrol digital. Sekali proses divider menghasilkan 36 adonan kecil dalam waktu 5 menit, dengan berat adonan masing-masing 40 gram. Dengan cara konvesional proses pengembangan adonan 4-5 jam, bahkan lebih kalau cuaca di luar mendung. Dengan menggunakan proofer yang dilengkapi dengan kontrol suhu dan kelembaban udara, maka proses ini hanya 2 jam.
\end{abstract}

\section{Keywords - adonan, bakpao, divider, proofer}

\section{PENDAHULUAN}

Bakpao adalah salah satu kue tradisional berasal dari Tionghoa yang disukai oleh masyarakat Indonesia termasuk masyarakat Jember karena disamping rasanya yang enak namun juga mampu mengganjal perut untuk menunda rasa lapar. Kue seperti ini berbentuk bundar dan mencembung pada bagian permukaanya sehingga terlihat ranum yang akan membuat kita semua dengan melihatnya saja pasti terasa ingin memakannya. Secara umum kue bakpao dibuat dari bahan baku tepung terigu, gula pasir, ragi, susu, garam dan pengempuk namun dalam perkembangannya bahan baku tepung terigu dapat disubstitusi dengan menggunakan tepung ubi jalar, tepung waluh atau tepung mocaf dengan komposisi 25 - $40 \%$ tepung substitusi dan 75 - $60 \%$ tepung terigu.

Ibu Hj. Supiyati dan Bapak Sodiq merupakan salah satu produsen bakpao sejak tahun 1996, keahlian membuat bakpao diperoleh dari ayahnya yang dulunya juga membuka usaha bakpao karena ayahnya pernah bekerja pada produsen bakpao dari seseorang yang keturunan Tiongha. Produksi bakpao pada awalnya hanya $6 \mathrm{~kg}$ bahan baku tepung terigu namun saat ini telah mampu memproduksi bakpao dengan

bahan baku utama tepung terigu sebanyak 20 $\mathrm{kg}$.

Dalam pembuatan bakpao terdapat proses pembagian adonan bakpao menjadi ukuran kecil. Selama ini mitra melakukan dengan cara menimbang satu persatu dengan ukuran berat yang sudah ditentukan. Adonan bakpao sebanyak 4,6 kg dibagi menjadi 6 bulatan besar, kemudian 1 bulatan besar ini dibagi menjadi 36 bulatan kecil dengan ukuran masing-masing bulatan 60 gram yang siap untuk dikukus.

Pembagian adonan bakpao menjadi ukuran kecil dilakukan dengan menimbang satu persatu adonan tersebut menggunakan timbangan kue. Pembagian adonan bakpao secara manual mempunyai banyak kelemahan yaitu: penimbangan 1 bulatan besar menjadi 36 bulatan kecil memerlukan waktu 30 menit, ukuran relatif tidak seragam, banyak bercampur tangan akan mengakibatkan panas 
pendahuluan. Hal ini akan mengakibatkan over fermentasi atau mengembang duluan, hal ini akan mengurangi mutu bakpao seperti aroma berkurang, tekstur kasar, rasa asam. Pembagian adoanan secara manual seperti tertera pada Gambar 1.

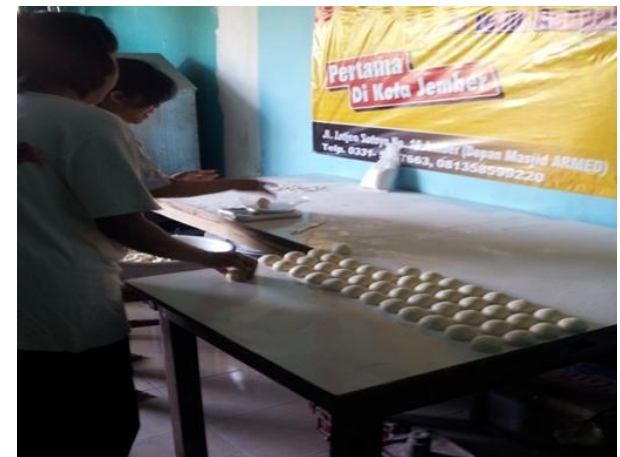

Gambar 1. Pembagian Adonan secara Manual

Selain itu pada proses pembuatan bakpao terdapat proses peragian atau fermentasi yang bertujuan agar adonan dapat mengembang. Pada tahap ini adonan mengembang karena adanya desakan gas CO2 yang dihasilkan khamir Sacharomyces cereviseae dengan substrat glukosa dari terigu ataupun gula, selain itu diikuti juga dengan terjadinya reaksireaksi biokimiawi menghasilkan asam-asam organik ataupun senyawa aromatis yang memberikan andil terhadap cita rasa bakpao. Selama proses fermentasi kondisi kelembaban dan suhu udara berpengaruh besar terhadap daya kembang bakpao, yaitu menghendaki RH $65-70 \%$ dan suhu ruang $30^{\circ} \mathrm{C}$. Pada umumnya industri kecil dalam melakukan proses fermentasi ini dilakukan dengan cara meletakkan adonan yang sudah dibentuk pada rak-rak dan ditutupi plastik, seperti tertlihat pada Gambar 2.

Kenyataan di lapang yang terjadi yaitu pada cuaca mendung fermentasi berlansung selama 6 jam, sedangkan pada cuaca normal berlangsung selama 4 jam. Sebenarnya apabila kondisi suhu dan kelembaban fermentasi ini terkontrol maka proses fermentasi hanya berlangsung paling lama 2 jam. Proses fermentasi yang lama ini menjadi keluhan pengusaha karena mengganggu proses produksi seperti: produksi menjadi lambat, sehari hanya mampu membuat 8 adonan yang dimulai pada jam 7.00 WIB pagi sampai jam 18.00 WIB, tenaga kerja pada waktu-waktu tertentu banyak yang nganggur. Dan kelemahan lain yang terjadi seperti: daya kembang kurang maksimal dan adonan bakpao terkadang lengket pada penutup plastik.

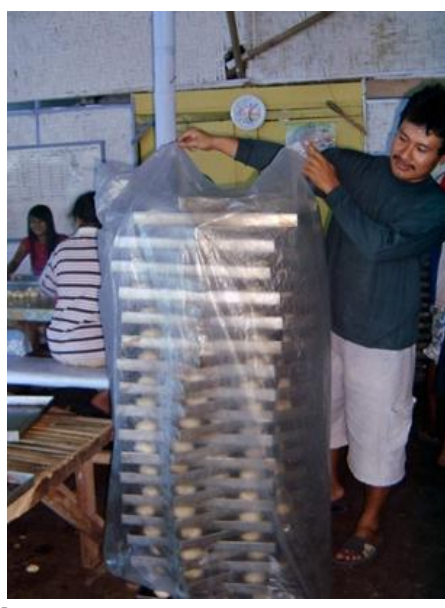

Gambar 2. Fermentasi Menggunakan Penutup Plastik

\section{TARGET DAN LUARAN}

Target luaran dari kegiatan ini adalah:

1. Terbuatnya satu unit Mesin Pembagi adonan bakpao (Gambar 2) dengan spesifikasi:

Dimensi (p,l,t): $(50,50,75) \mathrm{cm}$

Tenaga pembagi: sistim pneumatic

Rangka: Besi Siku 5x5, Besi U6 dan U5

Prinsip Kerja: Penekanan Multi Blade

Kapasitas : sekali tekan menjadi 36 buah bakpao

2.Terbuatnya satu unit lemari pengembang adonan proofer (Gambar 4) dengan spesifikasi:

Dimensi (p,l,t) : $(60,100,200) \mathrm{cm}$

Rangka: Pipa Kotak Stainles 3x3

Dinding: Plat Aluminium $1 \mathrm{~mm}$

Sumber panas: Heater listrik 100 watt

Pengukuran dan Kontrol Suhu: Termo Kontrol Digital

Kapasitas: 17 loyang sekali proses

Tujuan dari penerapan teknologi pembagi adonan bakpao adalah sebagai berikut :

a) Meningkatkan kapasitas pembagian adonan bakpao menjadi 36 bulatan kecil sekali tekan.

b) Meningkatkan keseragaman ukuran dan bentuk adonan

c) Menghindari terjadinya over fermentasi sehingga mutu bakpao lebih terjamin.

d) Memperbaiki sanitasi dan estetika produk.

e) Memperpanjang masa kadaluwarsa produk

f) Menciptakan kenyamanan kerja.

Tujuan pembuatan lemari pengembang (proofer) bakpao di industri rumah tangga adalah : 
a) Mempercepat waktu fermentasi menjadi 2 jam dan tidak terpengaruh oleh kondisi cuaca lingkungan

b) Meningkatkan kapasitas produksi menjadi 2 kali lipat dengan waktu produksi mulai jam 7.00 WIB sampai jam 16.00 WIB.

c) Suhu dan kelembaban udara fermentasi dapat dikontrol sesuai yang dibutuhkan yaitu, RH 65 - 70 \% dan suhu ruang 30oC.

d) Meningkatkan kualitas bakpao terutama bentuk dan rasa

e) Mengurangi resiko kegagalan dalam proses pembuatan bakpao,

f) Meningkatkan higienitas produk bakpao yang dihasilkan..

\section{METODE PELAKSANAAN}

Studi Pustaka dan Observasi Lapang

Dalam pembuatan alat pembagi adonan dan lemari pengembang bakpao diperlukan studi pustaka mengenai:

a) Sifat fisikokimia adonan bakpao

b) Teknologi perancangan alat mesin pencetakan bahan pangan.

c) Perhitungan daya, transformasi tenaga dan sistim transmisi

d) Teknologi pengolahan bakpao terutama pada proses fermentasi,

e) Teknologi perancangan alat pengembang (proofer) bakpao terkendali

f) Teknologi pengontrolan suhu dan kelembaban udara secara elektronik Studi lapang yang dilakukan adalah:

a) Mengamati proses pencetakan bakpao di tingkat industri kecil

b) Mengamati kualitas dan kuantitas adonan bakpao yang dihasilkan

c) Mengamati kondisi ergonomis dan efisiensi pembgian adonan bakpao secara manual di industri kecil

d) Mengamati kondisi pemasaran produk bakpao

e) Mengamati teknologi pencetakan/ pembagian bahan pangan yang ada dipasaran.

f) Mengamati proses pembuatan bakpao yang dilakukan di tingkat industri kecil

g) Mengamati kualitas dan kuantitas produk bakpao yang dihasilkan

h) Mengamati kondisi ergonomis dan efisiensi alat proses pembuatan bakpao yang ada di industri kecil terutama alat pengembang bakpao.

i) Mengamati teknologi pengembangan bakpao
Mesin Pembagi Adonan Bakpao Multi Blade (Divider)

Alat pembagi adonan bakpao yang akan diterapkan mempunyai keunggulan ukuran bakpao bervariasi sehingga besar bakpao yang dikehendaki dapat ditentukan. Prinsip kerja alat ini adalah untuk pembagian adonan menggunakan prinsip pembagian menggunakan pisau sekat yang ditekan kedalam adonan yang sudah diratakan pada sebuah tempat berbentuk lingkaran. Penekanan menggunakan sistem tuas pengungkit yang digerakkan oleh tangan. Dengan sistem ini tenaga penekanan tidak terlalu berat. Untuk lebih jelas teknologi yang akan dterapkan seperti pada Gambar 3a.

\section{Lemari Pengembang Bakpao (Proofer)}

Alat pengembang bakpao ini didesain mempunyai kapasitas 20 loyang selama 2 jam. Alat ini bekerja dengan prinsip pengkondisian udara ruang pengembang dengan parameter suhu dan kelembaban sesuai dengan kebutuhan proses pemgembangan bakpao. Pengukuran suhu dan kelembaban ini dilakuan secara elektronik. Dengan demikian secara garis besar alat ini terdiri dari beberapa bagian utama yaitu:

a. Unit Ruang Pengembang

Ruang pengembang berfungsi sebagai tempat terjadi proses fermentasi adonan bakpao. Pada ruang ini dibutuhkan suhu dan kelembaban tertentu. Ruang pengembang ini dibatasi oleh dinding yang terbuat dari aluminium. Dengan dinding model ini diharapkan suhu dan kelembaban akan lebih stabil. Selain itu dalam ruang ini dilengkapi rakrak tempat loyang bakpao, lampu penerangan dan kaca pengintai

b. Unit Pembangkit Kelembaban

Unit ini berfungsi untuk membangkitkan kelembaban untuk disalurkan keruang pengembang. Unit ini posisinya dalam alat pengembang berada dibawah ruang pengembang yang sekaligus berfungsi sebagai alas. Unit ini terdiri dari beberapa bagian yaitu: pemanas, bak air dilengkapi kipas pemercik dan blower untuk dihembuskan ke ruang pengembang. Pengendalian suhu dan kelembaban udara ruang pengembang dilakukan secara elektronik.

\section{KELAYAKAN PERGURUAN TINGGI}

Kinerja Lembaga Pengabdian Kepada Masyarakat Dalam Kegiatan PPM satu tahun Terakhir 
Kinerja P3M Politeknik Negeri Jember berkaitan dengan program Pengabdian Pada Masyarakat (PPM) dalam 1 tahun terakhir mampu mendapatkan program IbM dengan judul sebagai berikut:

a. IbM Kelompok Pengusaha Petis Ikan di Puger

b. IbM Kelompok Petani Sumberwaru Sukowono Jember

c. IbM Aplikasi Pakan Komplit Bentuk Wafer Untuk Meningkatkan Produktivitas Sapi Potong Di Kelompok Unit Pengolah Pupuk Organik (UPPO) Kabupaten Bondowoso

d. IbM Kelompok Tani Kopi Rakyat Desa Andongsari Kecamatan Tiris Kabupaten Probolinggo

e. IbM Kelompok Usaha Pengerajin Ikan Panggang dan Produsen Minyak Hati Ikan Hiu

f. IbM Usaha Tempe Di Desa Jurangsapi Dan Pejaten Kecamatan Tapen-Bondowoso

g. IbM Kelompok Usaha Ikan Asap Di Desa Paseban Kecamatan Gumuk Mas Kabupaten Jember

h. IbM Kelompok Petani Jamur Merang Rambipuji Jember

i. IbM Kelompok Usaha Pemindangan Tradisional

j. IbM Pengrajin Tempe Koro Metode Baru

k. Ibm Sistem Intensifikasi Padi (System of Rice Intensification $=$ Sri) Di Kelompok Tani

1. IbM Kelompok Tani Program Intensifikasi Sistem Mina Padi (Insismindi) Sistem Penjualan Berbasis Web Dalam Upaya Memperluas Jaringan Pemasaran Dan Meningkatkan Pendapatan Industri Batik Tulis Sumbersari Di Bondowoso

m. IbM Kelompok Pengusaha Kapuk Desa Manggis-Sukorambi

n. IbM Kelompok Peternak Kambing Rakyat Di Kecamatan Wuluhan Kabupaten Jember

o. IbM Kelompok Ternak Kambing Etawa Di Situbondo

p. IbM Peningkatan Jiwa Wirausaha Agribisnis Domba Di Lingkungan Pondok Pesantren

\section{HASIL DAN LUARAN YANG DICAPAI}

Dalam kegiatan pengabdian ini ada beberapa tahapan pekerjaan yang harus dilakukan meliputi: koordinasi dengan mitra, perancangan dan pembuatan mesin yang akan diterapkan, uji coba mesin, penyerahan, dan evaluasi. Dari tahapan kegiatan tersebut yang telah dicapai meliputi:

1. Koordinasi dengan mitra
Dalam pelaksanaan kegiatan pengabdian ini, tim selalu melakukan diskusi, meminta masukan dan juga saran. Hal ini dilakukan agar teknologi yang akan kita terapkan betul-betul digunakan oleh mitra dan mampu meningkatkan proses produksi baik dari segi kualitas maupun kuantitas. Dari hasil koordinasi ini mitra setuju dengan teknologi yang tim tawarkan.

2. Perancangan dan pembuaan alat

Dalam kegiatan pengabdian ini ada 1 unit mesin pembagi adonan (divider) dan 1 unit proofer yang akan diterapkan untuk dua mitra pengusaha bakpao di Tegal Besar. Dalam proses pembuatan mesin tersebut di atas ada beberapa tahapan yang dilakukan meliputi: perancangan, pemilihan bahan, pembelian bahan, pembuatan, perakitan dan uji coba.

3. Uji Coba Alat/Mesin

Uji coba dilakukan terhadap alat/mesin yang akan diterapkan agar beroperasi optimal pada proses pembagian dan pengembangan adoanan (mesin divider dan proofer).

\section{Penyerahan Mesin}

Setelah mesin divider dan proofer dapat beroperasi optimal diserahterimakan kepada mitra dengan menan-datangani berita acara serah terima (Gambar 4).

Dengan introduksi teknologi, pembagian adonan dilakukan dengan menggunakan alat pembagi adonan (divider). Sekali proses pembagian adonan akan menghasilkan 36 buah adonan, masing-masing adonan beratnya 40 gram dengan waktu proses 5-10 menit. Alat pembagi adonan seperti tertera pada Gambar 3 .

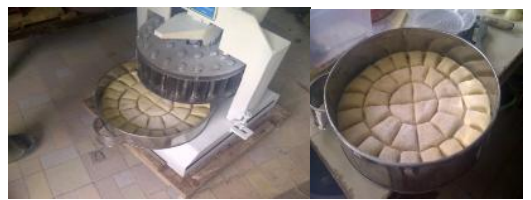

Gambar 3. Alat Pembagi Adonan (Divider)

Introduksi teknologi untuk proses pengembangan adonan adalah dengan lemari pengembang (proofer) yang dilengkapi dengan kontrol suhu dan kelembaban udara ruang pengembang (Gambar 4). Dengan menggunakan proofer akan menghasilkan bakpao yang berkualitas, sehat dan lebih higienis serta memperpendek waktu fermentasi dan mencegah terjadinya over fermented. 

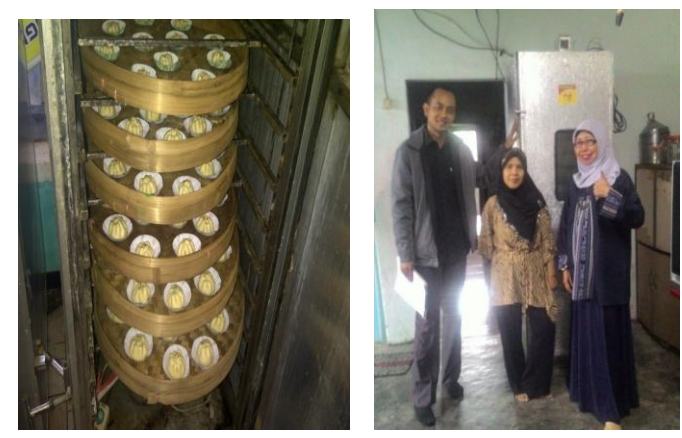

Gambar 4. Lemari Pengembang Adonan (Proofer)

\section{KESIMPULAN DAN SARAN}

\section{A. Kesimpulan}

Berdasarkan hasil kegiatan pengabdian yang telah dilasanakakan, disimpulkan bahwa:

1. Satu unit proofer dan satu unit divider sudah diserahterimakan kepada mitra Kelompok Pengusaha Bakpao di Tegal Besar

2. Alat pengembang adonan (proofer) dan pembagi adonan (divider) telah diimplementasikan oleh mitra sehingga dapat meningkatkan kualitas dan kapasitas produksi dan terjadi penghematan biaya operasional

B. Saran

Perlu adanya introduksi teknologi pemanfaatan steam pada mesin boiler untuk pengukusan pada proses produksi bakpao, sehingga hemat energi.

\section{UCAPAN TERIMA KASIH}

Terimakasih kepada:

1. Direktorat Penelitian dan Pengabdian Kepada Masyarakat, Direktorat Jenderal Pendidikan Tinggi, Kementerian Pendidikan dan Kebudayaan sebagai penyandang dana pengabdian Ipteks bagi Masyarakat (IbM).

2. Direktur Politeknik Negeri Jember

3. Kepa P3M Politeknik Negeri Jember beserta Staf

\section{Daftar Pustaka}

[1] Dennis R. Hildman and R. Paul Singh. 1980. Food Process Engineering. Second Edition. Avi Publishing Co. Inc., Westport. Connecticut.

[2] Henderson. S.M and R.L Perry. 1979. Agriculrure Process Engineering. John Willey and Sons. New York.

[3] Soewedo Hadiwiyoto. 1983. Hasil-hasil Olahan Susu, Ikan, Daging dan Telur. Liberty. Yogyakarta.

[4] Suharto. 1991. Teknologi Pengawetan Pangan. Rineka Cipta. Jakarta. 